\title{
AUTODIDACTIC FOR PARENTS OF CHILDREN STUDYING IN MULTI- ETHNIC SCHOOL ENVIRONMENT
}

Elena L. Grigoryeva ${ }^{1 *}$, Maria V. Lebedkina ${ }^{2}$, Oleg A. Musin ${ }^{3}$, Gennadij N. Germanov ${ }^{4}$, Al'bert R. Bajmurzin ${ }^{5}$

${ }_{1,2,3}$ Minin Nizhny Novgorod State Pedagogical University, Department of Physical Education Theoretical Foundations, Nizhny Novgorod, Russia, ${ }^{4}$ Russian State University of Physical Education, Department of Pedagogics, Sport, Youth and Tourism, Moscow, Russia, ${ }^{5}$ Russian State Social University, Department of the Theory and Technique of Physical Education, Moscow, Russia.

Email: ${ }^{1}$ gvelnn@ mail.ru, ${ }^{2}$ leopold_52@mail.ru, ${ }^{3}$ mysin332@mail.ru, ${ }^{4}$ genchay@mail.ru, ${ }^{5}$ miit511@mail.ru Article History: Received on $30^{\text {th }}$ August 2019, Revised on $28^{\text {th }}$ September 2019, Published on $22^{\text {nd }}$ October 2019

\begin{abstract}
Purpose: The article is aimed at describing a model of self-education of primary school children's parents and the results of its testing in a primary school in a multi-ethnic educational space. The leading technology of organizing self-education for parents of primary students and formation of their methods of auto-didactics is the technology of poly directional pedagogical counseling.
\end{abstract}

Methodology: The following methods of measuring the effectiveness of the offered program were used: SWOT - analysis of educational problems of primary school children in a multi-ethnic educational organization, analysis of research data on related topics, pedagogical modeling, studying students' work, observation, and survey methods with graphical interpretation of the data.

Result: The result of the study was a unique model of inclusion of primary students' parents in the educational space of a multi-ethnic school. In accordance with the authors' model, an awareness program was launched for parents of primary school children.

Applications: The research materials can be useful for primary school teachers, for parents of primary students, as well as for specialists in the system of additional education in working with multi-ethnic children groups, as well as for social teachers in working with migrant families to build a non-conflict educational environment.

Novelty/Originality: The originality of the study lies in the development of a model for the inclusion of parents of younger schoolchildren in the educational space of a multi-ethnic school through parental self-education organized by school teachers.

Keywords: autodidactic, multi-ethnic educational organization, activity of an advisory center, interaction of teachers and parents of primary school children, content and technology of education.

\section{INTRODUCTION}

The relevance of the study is determined by the fact that the lack of involvement of parents of primary school children in the educational space of a multi-ethnic school confirmed by a number of researchers (Gryaznova, 2010; Bayborodova, 2003) reduces the effectiveness of training and education processes and aggravates the following educational problems:

1. Parents' lack of awareness about the psychological state of their child and ways of helping them in an educational process ( $\underline{\text { Kim, 2013)}}$.

2. Insufficient knowledge of parents about how to involve a child in the process of developing their skills and abilities (Kirdyanova, 2015).

3. Insufficient use of methods for the physical development of children in the family during the extra-curricular time.

4. Poor parenting in principles and methods of home coaching.

Thus, the problem of the authors' research was the need to create a model for inclusion of parents of younger students representatives of indigenous and non-indigenous ethnic groups in the educational space of a school using the methods of autodidactic.

The purpose of this article is to determine the most effective methods of autodidactic for parents of younger schoolchildren that allow them to effectively integrate family and school efforts in teaching and raising children in a multi-ethnic educational organization and to identify pedagogical conditions of their formation and use.

\section{LITERATURE REVIEW}

As shown in the works of a number of researchers (Amonashvili, 2010; Da Costa and Sa, 2018; Dar et al., 2018; Aksenova, 2004; Kozyreva, 2018), parents experience difficulties in carrying out educational activities, either due to lack of education, or lack of research skills to identify the causes and consequences of their educational impact on the child. At the same time, as our study showed (Grigorieva and Bystritskaya, 2016), parents are motivated to educate themselves, but are poorly oriented in the modern information space, in the child's psychology, and also in the structure and the content of 
the educational process (Bystritskaya et al., 2016). Above mentioned findings became the basis for determining the most effective methods of autodidactic for parents.

Autodidactic is a set of mastered teaching methods used by the subject of educational activity (students) mainly in the process of self-education (Kurinsky, 2001, 2006). Parenting autodidactic is aimed at teaching and self-training parents to be able to identify whom, for what purpose, and also how and why they should carry out the educational process in the family. In the process of forming parents' autodidactic, they need to go through the following steps (Ghaderi et al., 2018; Ingavale, 2013):

1. Acknowledging and studying of problems arising from the lack of parents' readiness for the implementation of the upbringing process;

2. Understanding the gaps in their own pedagogical education;

3. The formation of the subjective position of parents in relation to the formation of the personality of their children;

4. Formation by parents of the subjective position of the child in the framework of joint activities mainly of a creative nature;

5. Determining the effectiveness of methods of autodidactic and family upbringing of a child.

Thus, the formation of autodidactic methods of parents inevitably leads to the formation of skills and methods of self-study of their children, which, ultimately, is the main goal of the pedagogical activity.

\section{RESEARCH METHODOLOGY}

The author's research was carried out in the period of 2015-2018 in multi-ethnic schools of the second type, where the representation of non-indigenous nationalities was from $15 \%$ to $25 \%$ of the total number of students. The study involved more than 1,200 parents of primary school children from the city of Nizhny Novgorod and Nizhny Novgorod region. The main technology of interaction between teachers and parents is the basic modular system (Bystritskaya et al., 2016), based on project activities, information technologies, with a focus on the values of health and physical development (Gavhale, 2016). The main methods in the model of integration of family and school education were the method of pedagogical counseling and the method of social and educational projects. SWOT - analysis of educational problems of primary school children in a multi-ethnic educational organization, analysis of research data on related topics, pedagogical modeling, study of students' work, observation and survey methods with graphical interpretation of the data obtained were used as research methods.

The experiment was carried out in three stages. At the first stage, a rating of problems interfering with the organizing of family and school interaction and the systemic self-education of parents was formed. At the second stage, the content of a modular type was formed and several access points were defined for the implementation in the process of educating parents in full-time and distance modes. In the third stage, the parents were informed of the content of educational and advisory activities. They were offered a choice of several methods of autodidactic allowing them to better understand the information important for the education, upbringing, and development of their children. At the end of this stage, the parents chose the most appropriate educational modules and methods for auto-teaching. At the stage of the formative experiment, the model was tested and its effectiveness was determined according to the following criteria:

1. Demand for the information;

2. The usefulness and applicability of the information in the context of family upbringing;

3. The intensity of self-education of parents;

4. The motivation for self-education of parents;

5. Their participation in extra-curricular activities;

6. The level of awareness of the educational activities for children carried out in school;

7. Expert evaluation of the effectiveness of family upbringing.

Each criterion was tracked at the beginning of the experiment, several times during the formative experiment and after its completion.

\section{Results}

As a result of a stating study, the attitude of parents to their children's upbringing was determined. The priority components of the upbringing of primary schoolchildren in the eyes of parents, as well as their level of awareness of these components, were identified. The results are shown in Table 1.

As follows from the data presented in the table, the attitude of parents of younger schoolchildren, as the axiological basis of family education, is formed among representatives of both indigenous and non-indigenous ethnic groups at a rather high level. It should be noted that parents, regardless of their nationality, do not have enough knowledge about the goals of 
upbringing, its directions and content, and the methods that can be applied in the framework of family upbringing. This problem was identified by questions about maintaining a healthy lifestyle. Parents of younger schoolchildren often have misconceptions about what methods should be used in family education in order to lead a healthy lifestyle with their children.

Table 1: Attitude of parents to the goals and content of their children's upbringing

\begin{tabular}{|c|c|c|c|c|c|c|c|c|}
\hline \multirow{2}{*}{$\begin{array}{l}\text { Component } \\
\text { of } \\
\text { Upbringing } \\
\begin{array}{l}\text { Educational } \\
\text { aspects }\end{array}\end{array}$} & \multicolumn{4}{|c|}{$\begin{array}{l}\text { Attitude to (points) } \\
(\max =9)\end{array}$} & \multicolumn{4}{|c|}{$\begin{array}{l}\text { Knowledge (points) } \\
(\max =9)\end{array}$} \\
\hline & To health & $\begin{array}{l}\text { To } \\
\text { intellectual } \\
\text { development }\end{array}$ & $\begin{array}{l}\text { To } \\
\text { communic } \\
\text { ation }\end{array}$ & $\begin{array}{l}\text { To the } \\
\text { development } \\
\text { of creative } \\
\text { skills }\end{array}$ & $\begin{array}{l}\text { About } \\
\text { healthy } \\
\text { lifestyle }\end{array}$ & $\mathrm{a}$ & $\begin{array}{l}\text { About } \\
\text { themselves } \\
\text { as an } \\
\text { example, } \\
\text { as a } \\
\text { teacher }\end{array}$ & $\begin{array}{l}\text { About the } \\
\text { system of } \\
\text { upbringing }\end{array}$ \\
\hline $\begin{array}{l}\text { Average } \\
\text { point }\end{array}$ & 8,6 & 4,9 & 4,5 & 8,1 & 2,3 & & 4,4 & 2,1 \\
\hline Level & High & Medium & Medium & High & Low & & Medium & Low \\
\hline
\end{tabular}

Parents have a weak idea of themselves as a teacher, whose personal example can be a worthy means of educational activity. Having a sufficiently high level of understanding of the significance of the educational potential of the creative activity of the younger schoolchild, in the process of its adaptation to the conditions of learning in a multicultural educational team and socialization in the Russian-speaking region, parents note that they have little knowledge of the mechanisms of inclusion in the creative process. At the same time, they realize that thanks to their creative activity, their children easily adapt to communication, learning, etc.

Paradoxically, it is precisely in those branches of knowledge and those areas of upbringing that are, in the opinion of parents of younger students, the most significant for their further education and socialization, they are least informed. Thus, the task of organizing parents' self-education in these areas on the basis of autodidactic methods arose.

To solve the problem, the authors developed a model for the inclusion of parents of younger schoolchildren representatives of non-indigenous ethnic groups in the educational space of the school. As part of the formative experiment, the approbation of the program of activities of the multicultural child-adult consultative center "Etno-Veche" was carried out. Classes were held with regularity once a week in a full-time mode. Individual counseling for parents was also carried out on individual issues related to the rehabilitation and socialization of children with the involvement of a school psychologist, a class teacher, and medical staff as required by the parents. The list of the participants in the consultations varied depending on its subject matter.

For example, the consultations on the inclusion of children in the work of the system of additional education of children's parents were allowed to attend. Only parents of students were present at the consultations on vocational guidance and professional self-realization of parents. Consultations held in the mode of masterclasses were organized for parents and children separately as well as joint. For example, not only 4th-grade students and their parents were present at the walking race master class, but also a fairly large number of middle and high school students who are brothers and sisters of the experimental group. All consultations had a different form of organization: informational and educational consultation, problem-oriented talk, training session, consultation held in the form of a business game and the form of master classes.

Presence of parents at the consultation:

1. Presence on the recommendation of a teacher who is aware of the problems of the adaptation and socialization of younger schoolchildren.

2. This is an individual choice of the consultations necessary for them according to the individual designer. The teacher determines the subject of mandatory consultations and consultations on the choice based on the results of introductory diagnostics.

Consultation designer is a table with topics, with a summary and a time for consultation. Parents choose these consultations at their own discretion, both individual and group, including the participation of children. The designer has three levels of counseling: introductory, which includes three consultations of choice, adapted - five consultations, and seven or more consultations is an advanced level. The authors of the model offer the structure of the consultation program implemented on an experimental basis - in a multi-ethnic child-adult center. Work on each substantive module was complemented by a collective educational event or a group socio-educational project, often on a competitive basis, in order to initiate parents to self-education.

The following methods were proposed for implementation: auto-control, goal-setting, self-motivation, self-evaluation, mutual evaluation, reflexive cooperation, analysis of one's own educational and social experience, the reflection of professional activity in socio-cultural coordinates and self-correction. 
Among the main problem-oriented content modules, as the study showed, the following were most in demand:

1. A psychological portrait of a junior schoolchild "Meet Your Child!". Problem: Considering individual properties of the temperament of the child in the educational process at school and at home. Activity: Self-diagnostics of temperament and character peculiarities according to K. Leonhard, learning express diagnostics and self-diagnostics of tempo rhythmic performance indicators. Result: Self-diagnostics and Self-actualization of psychological qualities, method of self-regulation inactivity.

2. Great is the glory of the nations. "I am proud of my heritage." Problem: Socialization of the family in the Russianspeaking region on the basis of a dialogue of ethnic cultures in history and modernity. Activity: Actualization and comparison of historical and cultural traditions of different nationalities with examples of national games, fairy tales, crafts. Result: Methods of expanding the cultural environment in the family using examples from other national cultures.

3. Organization of peace dialogue of cultures. "We are different, but we are together." Problem: Revealing and development of the creative potential of the family. Activity: Acquaintance with national crafts, Master class. Result: Methods of self-activation and self-improvement of creative abilities.

4. Basics of a healthy lifestyle. "I want my child to be healthy!" Problem: Expansion of the sector of health-forming technologies applicable in the conditions of family education. Activity: Introduction to health-forming technologies. Result: Methods of trial, self-diagnostics.

5. Fundamentals of the school service of restorative meditation. "... Better kind world!". Problem: Creating a safe environment in the family and in the sphere of wide social communication and interaction. Activity: Expanding information on safe behavior and the basics of restorative meditation. Result: Methods of family restorative mediation and building a favorable educational environment in the family.

6. Homemade food for a student. "There should be certain order and time for meals." Problem: Organization of healthy nutrition in the Russian-speaking region. Activity: Acquaintance with the annual cycle of healthy nutrition in the Russian-speaking region, taking into account the climatic conditions. The method of self-education in the field of aesthetics and recreational basics of cooking in the Russian-speaking region. Result: A method of training healthy eating habits in accordance with the social context of life activity.

7. Home education of a younger student. "Parent friend and teacher." The problem of integration of family and school education. Activity: The study of the theory of education and training on the basis of the authors' book "A book for parents." Result: Methods "dialogue with the author" and "apology draft".

8. Physical education of a younger student. "Physical culture - health, plus culture." The problem of the formation of a culture of health in the structure of family life. Activity: Diagnostics and design of family physical education programs for adult family members and children. Result: Methods of activity involving auto training (internal trainer).

9. GTO for the whole family. "Strengthen health together." The problem of the inclusion of the family in socially significant programs at various levels (federal, regional, etc.) aimed at the maximum adaptation and social adaptation of families in the Russian-speaking region. Activity: Introduction to socially significant projects. Result: Methods of projects, updating of experience and reflection.

10. Selection work in sports. "The road to the sport of higher achievements." Problem: Self-actualization and the search for ways to develop aptitudes. Activity: Acquaintance and workshop on the diagnosis of sports inclinations of younger students and other family members. Result: methods of self-diagnosis and diagnosis of aptitudes towards sports activities.

11. The discovery of the talent of a younger student. "The path to creativity." Problem: Self-actualization and the search for ways to develop abilities. Activity: Introduction and workshop on the diagnosis of creative and sports inclinations of younger schoolchildren and other family members. Result: Methods of self-diagnosis, diagnosis, and assessment of aptitudes and abilities for sports and creative activities.

Upon completion of the formative experiment, the results of the assimilation of autodidactic methods by parents in order to integrate family and school education systems were analyzed. Interestingly, the characteristics of this process among representatives of non-indigenous ethnic groups have undergone the maximum changes. The overall results are summarized in Table 2.

Table 2: Dynamics of involvement of parents of younger schoolchildren in the educational space of a multi-ethnic school of the second type (in \%).

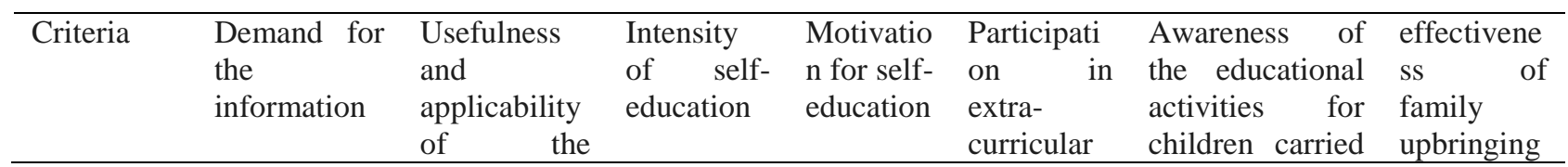




\begin{tabular}{|c|c|c|c|c|c|c|c|}
\hline & & infor & & & activities & out in school & \\
\hline $\begin{array}{l}\text { Before the } \\
\text { experiment }\end{array}$ & $42,4 \%$ & $69 \%$ & $21 \%$ & $18,7 \%$ & $14,2 \%$ & $35,3 \%$ & $39,4 \%$ \\
\hline $\begin{array}{l}\text { After the } \\
\text { experiment }\end{array}$ & $48,6 \%$ & $83 \%$ & $46 \%$ & $62,3 \%$ & $37 \%$ & $71,2 \%$ & $49,3 \%$ \\
\hline Final Level & Medium & High & Medium & High & Medium & High & Medium \\
\hline
\end{tabular}

As it is seen from the table, all the criteria for self-education of parents in applying the recommended methods of autodidactic during the implementation of the model for integrating family and school education have increased within reliable limits. The greatest attention is paid to the compliance of the information needs of the parents and the content of their help from teachers of professionals, as well as the involvement of parents in the process of educating children and to a lesser extent in the process of school education. Such a difference is justified since parents rely more on the school in matters of science-based education and get less involved in this process.

In the course of educational retrospection, more than $80 \%$ of parents used self-assessment, self-motivation, and goalsetting methods based on socially-approved criteria for behavior and activity to fill in the information. In the procedural plan, the parents of students used a variety of auto-didactic methods, among which the most popular were the trial method, the self-assessment method, and the self-motivation method.

\section{DISCUSSIONS}

During the implementation of the model, the parents of students of the multi-ethnic class had the opportunity to "try on" the methods of teaching and educating in a primary school in three aspects:

- Retrospectively. On the basis of the problems and tasks of education of their children, parents re-evaluate and rethink their own social educational experience in order to make it a substantive basis for applying the method of personal example in the structure of family education and training (Kirdyanova, 2015). At the same time, they consider not only the results of their activities, but also the procedural characteristics of their successful personal experience;

- Procedurally. Parents are included in the educational process, carried out within the framework of school activities and organizations of additional education. They analyze the goals of the problem, the process, and the results, of the educational activities of their child in order to integrate their efforts with the efforts of teachers in order to improve this process. Based on the analysis, parents also improve the methods of family education and upbringing;

- Forecasting. Parents learn about the goals and prospects for the further education of their children and build their activities and their self-education in accordance with these goals (Dmitriyev, Bystritskaya and Voronin, 2014).

When planning their possible participation in further educational activities and educational events at school, the parents carried out self-actualization and self-diagnosis of their creative abilities. The result of the planning was not only a desire to participate in the life of the school expressed by the parents but also the forms and content of such participation offered by them.

\section{CONCLUSION}

Based on the research, we can conclude that there is a problem of inclusion of parents of primary school children, representatives of non-indigenous ethnic groups in the educational space of a school. To solve this problem, a unique model was developed based on autodidactic with the use of consulting technology. The effectiveness of it was proved in the framework of the activities of a multi-ethnic children-adult counseling center, in a multi-ethnic educational organization MBOU Secondary School No. 5 in Nizhny Novgorod. As part of the implementation of the model, autodidactic methods which help to increase the effectiveness of the integration of the family and the school in matters of training and educating primary schoolchildren in a multi-ethnic educational organization were identified. The most demanded by the parents of primary students were the following methods: self-control, goal-setting, self-motivation, selfassessment, and self-correction. The following pedagogical conditions contribute to the formation of these autodidactic methods among parents of primary schoolchildren:

- Availability of "on-line" and "off-line" counseling;

- Variable forms of organization of advisory activities;

- Structuring the content of family and school interaction in the form of educational modules in accordance with the requirements of the Federal Educational Standards, social values of modern society, individual and age characteristics of students.

\section{RECOMMENDATIONS}

The article materials can be useful for primary school teachers, for parents of younger students, as well as for specialists in the system of additional education in working with multi-ethnic children groups, as well as for social teachers in working with migrant families to build a non-conflict educational environment. 


\section{ACKNOWLEDGMENT}

The author confirms that the data do not contain any conflict of interest.

\section{REFERENCES}

1. Aksenova, A.Yu. (2004). A role of ethnocultural traditions in moral education of modern school students: PhD thesis. St.Petersburg.

2. Amonashvili, Sh.A. (2010). School of Life. Theory and practice. Moscow: Bustard.

3. Bayborodova, L.V. (2003). Interaction of school and family. Yaroslavl: Akademiya Holding.

4. Bystritskaya, E.V. Burkhanova, I.Y., Voronin, D.I., Ivanova, S.S., and Grigoryeva, E.L. (2016). Rhizomemodular teaching of students as a basis of their professional creative self-consciousness formation. International Journal of Environmental and Science Education, 11(2): 85-94.

5. Da Costa, E.P., and Sá, S. (2018). Teacher Narratives on the Practice of Conflict Mediation. Advances in Intelligent Systems and Computing, 861: 156-169. https://doi.org/10.1007/978-3-030-01406-3 14

6. Dar, M., Masood, F., Ahmed, M.I., and Kabir, H.U. (2018). Zia Information and communication technology (ICT) impact on education and achievement. Advances in Intelligent Systems and Computing, 781: 40-45. https://doi.org/10.1007/978-3-319-94334-3_6

7. Dmitriyev, S.V., Bystritskaya, E.V., and Voronin, D.I. (2014). Tansversalny programs for an education system of undergraduates in the sphere of physical culture. Part 1: Not trained expert, and the developing professional is important. Vestnik of Minin University, 4(8): 28-41.

8. Gavhale, S. R. (2016). INEQUALITY OF GENDER RATIO AMONG RELIGIOUS AND SOCIAL GROUPS IN INDIA. Humanities \& Social Sciences Reviews, 4(2), 68-75. https://doi.org/10.18510/hssr.2016.422

9. Ghaderi, A., Kadesjö, C., Björnsdotter, A., and Enebrink, P. (2018). Randomized effectiveness Trial of the Family Check-Up versus Internet-delivered Parent Training (iComet) for Families of Children with Conduct Problems. Scientific Reports, 8(1): 11-14. https://doi.org/10.1038/s41598-018-29550-Z

10. Grigorieva, E.L., and Bystritskaya, E.V. (2016). the Concept of "Etno-Veche" within the child youth adaptation multiethnic center (association) "Ethnoglobe.Russian Federation". Scientific review. pedagogical sciences, 1: 7 21.

11. Gryaznova, VA. (2010). Socialization of the modern school student and personal example of the teacher. Collection. All-Russian pedagogical readings "Pedagogical heritage of Stepan Pavlovich Titov" Collection of materials, pp. 202-204.

12. Ingavale, D. (2013). An impact of advertisements on purchase decision of youth with reference to consumer goods. Advances in management, 3(1),18-22.

13. Kim, T.K. (2013). Organizational and pedagogical conditions of effective realization of problems of physical training in the family school system. Pedagogical education and science, 4: 57-64.

14. Kirdyanova, A.A. (2015). The system of interaction with family at school for parents "we together" as an innovation in additional education. Modern pedagogics, 7(32), 54-57.

15. Kozyreva O.A. (2018). Theorization in didactic and scientific and pedagogical knowledge. Vestnik of Minin University, 6(4): 5-13. https://doi.org/10.26795/2307-1281-2018-6-4-5

16. Kurinsky, VA. (2001). Autodidactics. St. Petersburg: Peter.

17. Kurinsky, VA. (2006). Post-psychological autodidactics. Lectures. Kiev: Post-psychological Institute of Global Culture.

18. Kutuev, R.A., Katicheva, M.G., Rassolov, I.M., Derdizova, F.V., Yevgrafova, O.G., and Kozhanov, I.V. (2016). Practical recommendations on students' tolerant behavior formation in universities. International Journal of Environmental and Science Education, 11(17): 10365-10376.

19. Troyna, B., \& Carrington, B. (2011). Education, racism and reform (Vol. 123). Routledge. https://doi.org/10.4324/9780203145944

20. Medugu, P. Z. The effect of boko haram activities on educational development in Madagali local government area of Adamawa State. 